\title{
URBANOGRAFÍA: EL CASO DE PEDRO SÁNCHEZ, DE PEREDA Y FORTUNATA Y JACINTA, DE PÉREZ GALDÓS
}

\author{
Fanny VIENNE VIÑALS \\ Universidad de Toulouse-II Le Mirail
}

\section{RESUMEN}

En el siglo diecinueve, la ciudad adquiere el estatuto de núcleo de la vida en España y suscita el interés de los literatos que vislumbran en su vasto escenario un material inagotable. Para llevar a cabo la tarea colosal de reconstrucción urbana a nivel literario, el autor decimonónico inserta, en medio de la trama narrativa, numerosas precisiones descriptivas o digresiones en las que queda patente el protagonismo de la ciudad en la que transcurre la acción. Pero además de estos habituales y usitados recursos literarios, florecen medios paralelos, de alcance casi insospechado, en el proceso de edificación urbana. Los personajes, entidades en constante movimiento, son efectivamente los que permiten asentar la existencia de un lugar y explorar los que todavía se distinguen por una pintura nebulosa e incompleta.

Palabras clave: Urbanografía, escritura, ciudad, espacio urbano, Madrid, protagonista, recorrido.

\section{ABSTRACT}

In the nineteenth century, the writers are interested in the city and got their inspirations from it. To pay tribute to the city in the literary world, the author inserted, through the narrative plot, numerous descriptions and digressions which put the city and its actions on a pedestal. Besides these usual and useful literary recourses, a number of other means flourish and contribute to build the city. The characters involved in constant movement are the ones which make you feel the existence of a place and explore a picture still blurred and incompleted.

Key words: Urbanography, writing, city, urban space, Madrid, characters, recourses. 
El autor es probablemente la primera instancia en edificar los muros de la ciudad literaria, en trazar las innumerables redes, vericuetos, callejones, calles y avenidas y en insuflar vida al conjunto ordenado que ve incorporarse paulatinamente bajo sus manos. Cuando deciden Pereda y Galdós establecer, respectivamente, uno de los puntos neurálgicos de su novela en la calle del Príncipe o en la plaza del Marqués viudo de Pontejos, alojando a la familia de Valenzuela o a la de Santa Cruz en estos dos lugares céntricos y concurridos del Madrid decimonónico, diseminan puntos claves e inmutables por un mapa que irá construyéndose con los pasos dados por los seres «sin carne ni hueso» (Pérez Galdós, 2001: 143) que pueblan el espacio urbano de Pedro Sánchez y Fortunata y Jacinta. La figura autorial dicta todas las acciones que llevan a la edificación de una ciudad literaria plenamente vivida y gozada por sus habitantes, y podría considerarse urbanógrafa total, por imaginar el inmenso tablero urbano antes de que se convierta en testigo y garante de los desengaños y regocijos de sus habitantes novelísticos.

Pero son los personajes los que realizan, conjuntamente y pese a sus diferencias intrínsecas, la totalidad de las exploraciones urbanas y los que se apropian, de manera efectiva, del territorio anteriormente imaginado por el escritor. «La ville se compose et se recompose, à chaque instant, par les pas de ses habitants», escribe Pierre Sansot (Sansot, 2009: 209), el filósofo francés, a propósito de nuestra ciudad diaria pero bien hubiera podido nacer este juicio de la observación de una ciudad literaria, una ciudad imaginada por Pereda o concebida por Pérez Galdós, y de sus habitantes más emblemáticos, el joven Pedro Sánchez o Juanito, el heredero de la acomodada familia Santa Cruz. Efectivamente, los habitantes se distinguen por su hegemonía en el proceso urbanográfico gracias a su predisposición a hormiguear por espacios múltiples, siendo hostiles las trayectorias, angostos los caminos o más amenos los lugares pisados, y por la constante efervescencia que acompaña cada uno de sus pasos en una ciudad vivida y escrita, pues, a escala humana. Una ciudad escrita a escala humana, desde el mismo pavimento, donde cada recorrido, aun el más lento e indeciso, contribuye a edificar el entorno urbano: ésta también es la visión defendida por Michel De Certeau:

C'est «en bas» [...], à partir des seuils où cesse la visibilité, que vivent les pratiquants ordinaires de la ville. Forme élémentaire de cette expérience, ils sont des marcheurs, Wandersmänner, dont le corps obéit aux pleins et aux déliés d'un «texte» urbain qu'ils écrivent sans pouvoir le lire. Ces praticiens jouent des espaces qui ne se voient pas; ils en ont une connaissance aussi aveugle que dans le corps à corps amoureux (Certeau, 2008: 141). 
Proliferan tanto los más ínfimos detalles antropológicos, sociales y relativos a los entes de ficción, como las precisiones topográficas a lo largo de los desplazamientos; las manifestaciones movedizas de la vida cotidiana, o las referencias a sucesos casuales, dan frecuentemente lugar a la evocación del entorno inmediato y permite, por consiguiente, nombrar claramente un espacio, asentando su existencia en el tablero urbano de la novela. Los personajes aceden así lógicamente al estatuto de urbanógrafas, al escribir la ciudad desplazándose. Los lugares mencionados se arraigan en el mapa vivido, en continua mutación, y van surgiendo cada vez más puntos fijos o facetas necesarios a la elaboración plausible de una ciudad literaria. En este sentido, son urbanográficos los trayectos diarios de la incansable Guillermina que recorre los cuatro puntos cardenales del Madrid de Fortunata y Jacinta en busca de materiales para edificar su asilo situado en la calle de Alburquerque, más allá de la glorieta de Bilbao, en Chamberí, o las sempiternas inspecciones comerciales de Estupiñá en todos los rincones o arterias comerciales, desde las plazas de la Cebada o la de Santa Cruz, hasta San Ginés, la Cava de San Miguel o la Cava Baja, el Portillo de Gilimón e incluso la lejana y extensa calle de Toledo.

La presencia, efímera o duradera, recurrente o esporádica, de un protagonista en un lugar determinado es probablemente la percepción más sencilla de una urbanografía que raya con conceptos más complejos. Si no sorprende ni provoca reacciones descomunales el afirmar que la presencia de un ser de ficción, en un lugar dado, da cuenta de la potencia creadora del mismo lugar, provocaría, sin embargo, interrogaciones o negaciones vehementes el certificar, de buenas a primeras, que la ausencia de un protagonista o el carácter desértico de un lugar también forman parte de la colosal empresa urbanográfica. El denominador común y el elemento que racionaliza esta última afirmación es el protagonista. Pero antes de alcanzar y asegurar tales extremos, emprendamos vías transitorias, donde la presencia de un protagonista se une a la omisión de datos sobre el lugar en que se encuentra, o por el que va pasando, sin que se altere la propagación gráfica.

En un fragmento de la novela perediana, Don Serafín Balduque y Pedro Sánchez salen juntos de un espacio privado definido como suyo por el narrador gracias a la anteposición del posesivo «mi» al sustantivo «casa», en una frase que se pierde por el raudal de palabras derramadas: «bajaba las escaleras de mi casa» (Pereda, 1965: 61). Esta casa explícitamente ubicada, unas páginas antes, en la calle del Caballero de Gracia (Pereda, 1965: 47), es uno de los múltiples puntos de referencia del mapa urbano de la novela. Se erige paralelamente a varios otros, como la casa de don Serafín y su hija, situada en la calle del Olmo. Estos dos puntos de referencias, el de partida y el de llegada, 
representan, lacónicamente, un camino recorrido repetidas veces a lo largo de la obra por ambos protagonistas masculinos. Si el morar en cada uno de estos dos lugares asienta su existencia de manera innegable, las informaciones sobre el trayecto elegido, mayoritariamente tácitas o elípticas, establecen una continuidad en el mapa urbano. Pese a su aparente distancia respecto a la escritura urbanográfica, los movimientos evocados sin precisión geográfica alguna - como lo sugieren estas palabras de Pedro Sánchez, pronunciadas por el camino que les lleva a casa de su amigo: «atravesando calles y enterándome del nombre y calidad de cada una de ellas, llegamos al número 42 de la del Olmo» (Pereda, 1965: 61) — reivindican legítimamente su pertenencia a la urbanografía, su implicación en el trazado topográfico de la ciudad literaria.

La distancia entre la calle del Caballero de Gracia y la del Olmo acentúa las combinaciones direccionales; el lector no puede saber a ciencia cierta cuál de los trayectos opcionales habrán emprendido los dos entes peredianos; si los callejones apartados e impregnados del carácter castizo o las calles principales igualmente garantes de una identidad singular. Llegaron sanos y salvos nuestros hombres, librándose de nuestro meandro callejero y subieron, por fin, a la casa de la calle del Olmo, donde se entretuvieron largo rato con Carmen, abarcando temas tan opuestos como su afición por el teatro como la cesantía de su padre.

Llegó la hora de despedirme de ella, y salí con don Serafín a la calle. Recorrimos otras muchas, siempre bajo la dirección de mi amigo, que se complacía en no llevarme dos veces por una misma; y en la de la Magdalena nos detuvimos delante de una fachada medio cubierta de carteles (Pereda, 1965: 65).

Se reducen, en este caso, las posibilidades de trayectorias por la proximidad de los dos lugares. A pesar de la travesura de don Serafín, tan locamente enamorado de su ciudad o, por lo menos, lo suficientemente como para alargar el recorrido, se agotarán las combinaciones a medida que irán recorriendo este trayecto y, en el presente caso, eliminando la calle de Santa Isabel, que conduciría directamente a la de la Magdalena, son tres las calles que podrían eventualmente caber en el plural de Pedro Sánchez: «recorrimos otras muchas»: la del Olivar, la del Ave María y la calle de Santa María de la Cabeza. Sin embargo, son éstas disquisiciones - o presunciones - tan interminables como el laberinto de calles susceptibles de haber presenciado los pasos de don Serafín y Pedro Sánchez. «La calle no importa» (Pérez Galdós, 2007: 441), le contesta Villalonga, el protagonista galdosiano, a Juanito Santa Cruz cuando le pregunta éste dónde vio a Fortunata. Resuena el eco de la voz algo desenvuelta de Villalonga hasta el presente estudio. Efectivamente, no importa el nombre de la calle; se desvanece bajo los pasos de unos protagonistas 
sumidos en pensamientos o pláticas que les impiden escrudiñar cada esquina o alzar continuamente la mirada hacia los rótulos que indican los nombres y números de las calles. En efecto, el pobre Maximiliano Rubín está muy ajeno a preocupaciones de índole topográfica cuando, tras haber encontrado por primera vez a Fortunata en casa de Feliciana, sale frenéticamente a la calle con la única esperanza de alcanzar a la joven que acababa de salir.

Llegó sin aliento al portal y allí dudó si debía tomar a la derecha o a la izquierda de la calle. El corazón le dijo que fuera hacia la calle de san Marcos [...]. Anduvo calles y calles, retrocedió, dio vueltas a ésta y la otra manzana, y la dama nocturna no parecía (Pérez Galdós, 2001: 467).

El mismo Maximiliano sufre una alergia patológica y visceral al trato social; le asfixia su timidez al verse encerrado en espacios privados o proclives a reuniones de más de tres personas.

Por esto le gustaba más, cuando el tiempo no era muy frío, vagar por las calles, embozadito en su pañosa, viendo escaparate y la gente que iba y venía, parándose en los corros en que cantaba un ciego [...]. Andar, andar y soñar al compás de las piernas, como si su alma repitiera una música cuyo ritmo marcaban los pasos, era lo que a él le deleitaba (Pérez Galdós, 2007: 460).

Este joven enclenque halla su única salvación en el echarse a las calles. Se convierte, pues, lógicamente en una figura urbanográfica. Su miedo a la muchedumbre, al que se irán añadiendo trastornos mentales, determina reacciones inmunitarias creando una visión modificada de la ciudad por la que va pasando. Maxi, al perderse por las calles y al deleitarse en la contemplación de un espectáculo urbano, adquiere uno de los estatutos más significativos de la urbanografía vacía de toda referencia precisa: el del flâneur, figura tan mimada por Walter Benjamin (Benjamin, 1971; Benjamin, 1972).

El carácter urbanográfico de estos movimientos no se reduce ni se anula con la ausencia de datos referenciales. Los entes de ficción se mueven por un espacio muchas veces insertado en la narración con el mero término genérico «calle» pero la presencia momentánea de un personaje en un lugar determinado basta para añadirlo al mapa: se tejen redes urbanas sin que sea necesario aclarar su identidad. Si este tipo de movimientos carece de datos respecto a los demás, como los explícitamente mencionados —el incesante vaivén por la calle del Príncipe o por la plaza del Marqués viudo de Pontejos-, no por ello dejan de ser imprescindibles a la escritura de una ciudad total.

Los personajes son, indudablemente, el axioma de más valor en la empresa urbanográfica; los lugares por ellos ocupados y después relegados a esferas segundarias, según la evolución del relato que supone una constante reorganización y utilización del espacio, pertenecen al mapa urbano desde el 
momento en que lo pisan los protagonistas - y desde que se nombran- por primera vez. En Fortunata y Jacinta, cuando las críticas de Segismundo Ballester, el licenciado en farmacia que dirige la botica de Samaniego en la calle del Ave María, obligan a Maxi a que salga del establecimiento, por la dureza de su contenido y la insistencia del proferir, y a que se refugie, acto seguido, en casa de su tía, situada en la misma calle, se desvanece evidentemente la escena de la farmacia. El diálogo entablado posteriormente por doña Lupe lleva la acción hacia otros horizontes y acentúa de hecho la borrosidad de un recuerdo no tan lejano en el tiempo. Sin embargo, si arroja un velo este diálogo sobre la farmacia, no la hunde en un abismo ni borra la existencia de Ballester y de sus preparaciones cuando se hallan éstos fuera del énfasis de la acción. Entrarán otros clientes a pedir medicamentos a base de diaquilón, alcohol de coclearia o cuantas sustancias parecidas, hasta que se vuelva a proyectar el foco de la acción sobre la tienda y este singular personaje.

En Fortunata y Jacinta, el ejemplo más convincente de este palpitar subterráneo y de esta escritura urbana paralela a la acción es, sin lugar a dudas, el de Guillermina. La «rata eclesiástica» se implica cuerpo y alma en la construcción de un asilo en la calle de Albulquerque. Siempre corre por doquier, paralelamente al desarrollo de la acción e irrumpe fugazmente en las escenas, para despedirse en seguida de los protagonistas presentes a su alrededor con una fórmula lacónica y familiar: «No, yo no paso. No, Tengo que irme al momento a la obra» (Pérez Galdós, 2007: 72). Su presencia efímera anuncia un desdoblamiento urbanográfico; en el presente caso, la acción seguirá en el casco urbano y más precisamente en la plaza del Marqués viudo de Pontejos, mientras que otra ramificación de la escritura de la ciudad se orientará, implícitamente, hacia Chamberí. El mismo procedimiento establece otra escritura paralela de la ciudad más adelante en la novela. Guillermina está con doña Lupe, Fortunata y Jacinta en la calle de Mira el Río, donde guarda cama la pobre Mauricia. Fiel a la habitual inestabilidad geográfica de su «odisea filantrópica» (Pérez Galdós, 2007: 295), Guillermina es la primera en despedirse de las demás «para ir al almacén de maderas de la Ronda» (Pérez Galdós, 2007: 206). Si se anuncia claramente otra etapa de la vía crucis de la Santa, las andanzas de la solitaria «rata eclesiástica» por la Ronda de Toledo sólo cobrarán vida por la confianza que el lector deposita en la determinación y energía de esta mujer capaz de recorrer cualquier distancia con el fin de encontrar materiales para acabar el edificio. Esta urbanografía operante en la oscuridad, simultáneamente a otra, radiante, se revela también a posteriori, como en el presente fragmento donde Fortunata, mientras está su amiga en la estación de las Pulgas, explica la razón de su presencia en aquel lugar, aludiendo a acontecimientos anteriores: «Había 
recibido dos vagones de sillares y obtenido del director de la Compañía del Norte que le hicieran la descarga gratis con las grúas de la empresa... ¡Los pasos que tuvo que dar para esto!» (Pérez Galdós, 2007: 361). Cualquier que sea el método empleado; indicación de un desarrollo simultáneo - pero enteramente tácito-, anuncio o relación a posteriori, el asilo se construye al margen de las historias principales de la novela. No es durante las raras visitas de los amigos de Guillermina ni durante las escasas focalizaciones detenciones en las obras cuando se edifica el monumental asilo de Chamberí como lo sugieren estos pensamientos de Jacinta, preocupada por las dificultades que disminuyen las probabilidades de adoptar al Pituso:

Al volver a su casa, tenía la Delfina vivos deseos de saber si Guillermina había hecho algo. Llamóla por el balcón; pero la fundadora no estaba. Probablemente, según dijo la criada, no regresaría hasta la noche porque había tenido que ir por tercera vez a la estación de las Pulgas, a la obra y al asilo de la calle de Alburquerque (Pérez Galdós, 2007: 379).

Las reflexiones puestas de realce por la potencia creadora de la ausencia, de la omisión y de lo tácito llevan a considerar múltiples formas de construcciones simultáneas de una ciudad literaria. La validez de estas observaciones estriba en la aceptación y en la revalorización de un allí cuya importancia ya no se vería desterrada tan lejos como la distancia intrínseca al sentido de esta palabra. La debilidad a escala humana de un protagonista incapaz de abarcar con la mirada la totalidad de la cartografía urbana no niega la existencia de un alli ${ }^{1}$. El conocimiento o la imaginación permiten esbozar mentalmente las manifestaciones y los rincones de la urbe que quedan fuera del alcance de la mirada; éstos son los únicos medios de los que disponen el habitante, el protagonista, o el lector, para reconstruir la ineluctable visión fragmentada que tiene de su ciudad. Las palabras del medievalista, Paul Zumthor, corroboran esta teoría: «autour du lieu, où j'éprouve en cet instant mon enracinement dans le cosmos, je connais ou imagine tous les autres» (Zumthor, 1993: 52).

La acción visual totalizadora va reservada a una instancia superior... a la que De Certeau dedica otras líneas:

Celui qui monte là-haut sort de la masse qui emporte et brasse en elle-même toute identité d'auteurs ou de spectateurs. Icare au-dessus de ces eaux, il peut ignorer les ruses de Dédale en des labyrinthes mobiles et sans fin. Son élévation le transfigure en voyeur. Elle le met à distance. Elle mue en un texte qu'on a devant soi, sous les yeux, le monde qui ensorcelait et dont on était «possédé». Elle permet de le lire, d'être un EEil solitaire, un regard de dieu.

1. Véase al respecto el maravilloso texto de Ortega y Gasset, donde se detalla la noción del allí con la metáfora del bosque (Ortega y Gasset, 1975: 76-86). 
Exaltation d'une pulsion scopique et gnostique. N'être que ce point voyant, c'est la fiction du savoir (Certeau, 2008: 140).

El lector, instancia superior bicéfala, se mueve como Teseo por los lugares recónditos de la urbe laberíntica y vuela como Ícaro por encima de la ciudad literaria. Reúne, en un último esfuerzo urbanográfico, las visiones fragmentadas y detallistas de la ciudad proporcionadas por los protagonistas, en un conjunto de tendencia panóptica. Tendencia evidentemente lejos de constituirse en realidad efectiva; la ciudad total de Galdós, y aún más la de Pereda, integran la ausencia y edifican también sus muros sobre superficies definitivamente tácitas.

\section{BIBLIOGRAFÍA}

Benjamin, Walter, Angelus Novus, Barcelona, Edhasa, 1971.

BENJAMIN, Walter, Iluminaciones II. Baudelaire, un poeta en el esplendor del capitalismo, Madrid, Taurus, 1972.

Certeau, Michel de, Linvention du quotidien. 1. Arts de faire, París, Gallimard, 2008.

Ortega y Gasset, José, Meditaciones del Quijote, Madrid, Aguilar, 1975.

Pereda, José María de, Pedro Sánchez, Madrid, Espasa Calpe, 1965.

PÉrez Galdós, Benito, El amigo Manso, Madrid, Cátedra, 2001.

PÉrez Galdós, Benito, Fortunata y Jacinta, Madrid, Cátedra, 2007.

SANSOT, Pierre, Poétique de la ville, París, Payot \& Rivages, 2009.

Zumthor, Paul, La Mesure du monde. Représentation de l'espace au Moyen-âge, París, Seuil, 1993.

Fecha de recepción: 20-1-2012

Fecha de aceptación: 5-5-2012 